\title{
The Effect of Self-Identity on Online-Shopping Addiction in Undergraduates: Taking Guangdong Province as an Example
}

\author{
Yongmei Hou ${ }^{1, *}$ and Xiaoyu Yang ${ }^{1}$ \\ ${ }^{1}$ Department of Psychology, School of Humanity and Administration, Guangdong Medical University, Dongguan \\ Guangdong \\ *Corresponding author Emai: wdtgxx_1187333 @ 163.com
}

\begin{abstract}
With the rapid development of e-commerce and smart phones, online shopping is becoming an increasingly important pattern of consumption and plays a profound role in influencing individual's behaviors, thinking and personality development. The aim of this study is to explore the status of undergraduates' self-identity and online-shopping addiction, and analyze the relationship between the above two variables. Totally 1183 undergraduates were selected by random sampling from 3 colleges in Guangdong Province. They were investigated with Self-Identity Scale (SIS), Online-Shopping Addiction Questionnaire for College Students (OSAQ) and Adolescents Pathological Internet Use Scale (APIUS). The survey results indicate the following two points. First, the incidence of online shopping addiction was $16.7 \%$; the self-identity of $12.8 \%$ college students was in a state of positive delaying, while that of $0.5 \%$ was in a state of identity completion. Second, multiple linear regression analysis showed that the scores of each dimension of SIS were negatively correlated with the total score of OSAQ $(\beta=-.101 \sim-.229, \mathrm{P}<.05)$. It is therefore suggested that online shopping addiction is a common Internet behavioral problem in college students and the improvement of self-identity may be a protective factor of college students' online shopping addiction.
\end{abstract}

Keywords: Undergraduates, Online Shopping Addiction, Self-Identity

\section{INTRODUCTION}

With the rapid development of e-commerce and smart phones, online shopping, being fast and convenient, has become an indispensable pattern of consumption [1], and college students have become the key users of online shopping [2].

While bringing convenience to people, online shopping gives rise to a variety of behavioral and psychological problems [3-6]. Online shopping addiction is one of the most common behavioral problems. According to a survey published by China Youth Daily, up to $90 \%$ of the interviewees have online shopping experience, $71.1 \%$ think that their current status has met the characteristics of online shopping addiction, and a small number have been self-rated with serious online shopping addiction behaviors [7].

Some scholars believe that online shopping addiction results from the Internet users' "superstition" with online shopping commodity [8]. Online shopping addicts obtain more happiness from continuous purchase and unlimited possession. Their purchasing behavior belongs to their own without the participation of others. One of the important reasons why online shopping is popular with them is that online shopping will make them feel "the whole world serves me", which helps them to ease their emotions and enhance their sense of being noticed [9]. Online shopping addicts' shopping passion is obviously affected by online shopping advertising and brand marketing. In particular, some "Internet sensational goods", through the vigorous promotion of various media, shapes the so-called consumer personality and identity, and forms the consumption logic of "buy to enjoy", thus producing a huge buying bandwagon effect, namely, "commodity superstition", which will exert a tremendous impact on the consumer autonomy and choice of online shopping addicts. It can be seen that unreasonable self-awareness is an important reason for online shopping addiction: because they cannot correctly understand themselves, cannot clearly understand their own needs, and cannot obtain identity

recognition in the real world, online shopping addicts can only obtain "identity recognition" with the help of commodities and online shopping behavior, and strengthen their illusory narcissism [8-9].

Erikson believes that self-identity is a high-level form of self-consciousness, which means that individuals integrate their past, present and future to produce the continuity, maturity and sense of integration of personality development, that is, the integration and coordination of individuals' internal state and external environment. The completion of self-identity means that individuals have a full understanding of themselves, can organically integrate 
their real self and ideal self together, so as to determine their ideals and values, and make their own thinking about the future development [10].

Marcia manipulates Erikson's view of self-identity and creates a theoretical model of the states of self-identity, which divides into four kinds of identity states and puts forward the theory of types of identity states according to the two dominant dimensions of Erikson's theory of self-identity, namely, the level of exploration and the level of engagement [11]. On the basis of Marcia, Azushi Kato adds the dimension of "current desire for self-involvement ", and divides self-identity into six states: identity diffusion, intermediate state between identity diffusion and positive delaying, positive delaying (also known as "psychological delaying period"), authority acceptance, intermediate state between authority acceptance and identity completion and identity completion [12]. Youth's self-identity shall be in a positive delaying position. If the formation of self-identity is not completed in adolescence, the time of undertaking social responsibility can be delayed. During the transition period from adolescence to youth, appropriate "pause" can be selected to avoid hasty exercise and form identity rashly [13].

Erikson believes that all psychological and behavioral problems of adolescents and young people are closely related to self-identity [10]. The most critical change of self-identity occurs in the middle or late stage of adolescence, and the main period to create a stable sense of identity is around 20 years old. Therefore, college students are experiencing an institutionalized delaying period [14]. During this period, college students can actively experience life and try to form a stable and continuous identity. With the aggravating changes of society, college students encounter more and more difficulties and confusion in the formation of self-identity, which results in more prominent problems. College students often lack the criteria of independent judgment and the direction of predetermined action for values, which leads to a series of behavioral and psychological problems. Among them, Internet addiction (including online shopping addiction) is the most common psychological problem [15-16].

To sum up, Internet addiction and online shopping addiction are common psychological and behavioral problems among college students. From the perspective of development psychology, these problems are closely related to the state of college students' self-identity. This study aims to confirm the effect of self-identity on online shopping addiction.

\section{RESEARCH OBJECT AND METHOD}

\subsection{Research Object}

\subsubsection{Sample Size Estimation}

The minimum sample size is calculated by $\mathrm{G} *$ Power 3 [17]. As the detection rate of online shopping addiction among domestic college students is $9.83-24.58 \%$ [18-20], the test effect value is at medium level [18-20], that is, $d$ value is $0.50-0.80 \quad[21]$. In this study, we set the effect value $d=0.70$, the statistical test force $1-\beta=0.80$, the type I error probability $\alpha=0.05$, and the minimum sample size is calculated as 748. The minimum sample size is determined as 898 due to $20 \%$ of possible follow-up loss rate.

\subsubsection{Sampling}

From April to June, 2018, a total of 1250 questionnaires were distributed to college students from freshmen to the fifth year from Dongguan University of Technology, Guangdong Medical University and Guangdong University of Petrochemical Technology by random sampling. 1183 valid questionnaires were collected, with an effective rate of $94.5 \%$. There were 563 males and 620 females; 248 freshmen, 262 sophomores, 246 juniors, 224 seniors, 203 fifth year students; 554 students from urban areas and 629 students from rural areas.

\subsection{Tools}

\subsubsection{Self-Identity Scale, SIS}

It is compiled by Azushi Kato and revised by ZhANG Risheng [13] into Chinese version. There are 12 questions, divided into three dimensions: "the desire of future self-engagement (DFSE)", "past crisis (PC)" and "present self-engagement (PSE)". The scores of these three dimensions determine six self-identity states (status): A state (identity completion), A-F state (intermediate state between identity completion and authority acceptance), $\mathrm{F}$ state (authority acceptance), M state (positive delaying state), D-M state (intermediate state between identity diffusion and positive delaying) and $\mathrm{D}$ state (identity diffusion). The Likert 6-point scoring method is used to score from 1 to 6 points corresponding to "not at all" to "completely yes". The higher the total score, the higher the degree of self-identity completion. In this study, the Cronbach's $\alpha$ of the total scale is 0.81 , and the Cronbach's $\alpha$ of each dimension is $0.73-0.79$.

\subsubsection{Online-Shopping Addiction Questionnaire for College Students, OSAQ}

Compiled by XU Lang (2014) [22], OSAQ has 22 questions, divided into four dimensions: online shopping pleasure (OSP), excessive consumption (EC), abstinence reaction (AR) and functional impairment (FI). The Likert 5 -point scoring method is used to score from 1 to 5 points corresponding to "completely non-compliant" to "completely compliant". The higher the total score, the deeper the degree of online shopping addiction. The total 
average score of the scale is 4.00 as the standard, and any score higher than 4.00 is regarded as online shopping addiction. In this study, the Cronbach's $\alpha$ of the total scale is 0.94 , and the Cronbach's $\alpha$ of each dimension is $0.78-0.86$

\subsubsection{Adolescents Pathological Internet Use Scale, APIUS}

APIUS is compiled by LEI Li et al. (2007) [23]. It has 38 questions, divided into six dimensions: salience, tolerance (ST), compulsive Internet/abstinence symptoms (CI), mood change factors (MCF), social comfort (SC) and negative consequences (NC). The Likert 5-point scoring method is used to score from 1 to 5 points corresponding to "completely non-compliant" to "completely compliant". The higher the total score, the deeper the degree of Internet addiction. Total average score $<3$ is deemed as normal; 3 $\leq$ total average score $<3.15$ is deemed as marginal state; total average score $\geq 3.15$ is deemed as addiction. In this study, the Cronbach's $\alpha$ of the total scale is 0.92 , and the Cronbach's $\alpha$ of each dimension is $0.81-0.88$.

\subsubsection{Self-compiled Personal Information Questionnaire}

It includes 4 items, namely, gender, grade, origin and university.

\subsection{Data Processing}

SPSS 20.0 was used to analyze the valid data. Descriptive statistics were used to calculate the number of college students in each score segment of each scale; Pearson product-moment correlation coefficient was used to explore the correlations between variables; multiple stepwise linear regression analysis was used to explore the relationship between self-identity and online shopping addiction of college students.

\section{RESULTS AND ANALYSIS}

\subsection{The Current Status of College Students' Internet Addiction, Online Shopping Addiction and Self-identity}

According to the APIUS scoring standard, 309 (26.1\%) college students were judged with Internet addiction, 44 $(3.7 \%)$ were in marginal state, and $830(70.2 \%)$ were normal. Among 309 students with Internet addiction, 198 (127 females) had an average score higher than 4.00. It can be seen that the incidence of online shopping addiction was $16.7 \%, 20.5 \%(127 / 620)$ in females and $12.6 \%$ $(71 / 563)$ in males. The incidence of online shopping addiction in females was significantly higher than that in males $(\chi 2=13.123, \mathrm{P}<0.001)$.

According to the score of SIS, there were $6(0.5 \%)$ people in identity completion, $134(11.3 \%)$ in authority acceptance - identity completion, $10(0.8 \%)$ in authority acceptance, $151(12.8 \%)$ in positive delaying, $762(64.4 \%)$ in identity diffusion-positive delaying intermediate state, and $120(10.2 \%)$ in identity diffusion.

\subsection{Correlation Analysis of OSAQ and SIS Scores}

It can be seen from Table 1 that the correlation of past crisis vs. online shopping pleasure, past crisis vs. functional impairment, and the desire for future self-engagement vs. functional impairment was not significant. The total scores of SIS and other dimensions were significantly negatively correlated with the total score of OSAQ and other dimensions $(\mathrm{r}=-0.143 \sim-0.396, \mathrm{P}$ $<0.01)$.

Table 1. Correlation Analysis of OSAQ and SIS Scores

\begin{tabular}{|c|c|c|c|c|c|}
\hline & OSP & $\mathrm{EC}$ & AR & FI & OSAQ Total Score \\
\hline PSE & $-0.384^{* *}$ & $-0.396^{* *}$ & $-0.318^{* *}$ & $-0.220^{* *}$ & $-0.254^{* *}$ \\
\hline $\mathrm{PC}$ & -0.083 & $-0.265 * *$ & $-0.223 * *$ & -0.084 & $-0.143 * *$ \\
\hline DFSE & $-0.236 * *$ & $-0.378 * *$ & $-0.319 * *$ & -0.094 & $-0.211 * *$ \\
\hline SIS Total Score & $-0.159 * *$ & $-0.332 * *$ & $-0.269 * *$ & $-0.144 * *$ & $-0.249 * *$ \\
\hline
\end{tabular}




\subsection{Regression Analysis of College Students' Online Shopping Addiction and Self-identity}

Taking the total score of OSAQ as the dependent variable and the score of each dimension of SIS as the independent variables, the multiple stepwise linear regression analysis was conducted. The results showed that there was a significant negative correlation between each dimension of SIS and the total score of OSAQ $(\beta=-.101 \sim-.229$, all $\mathrm{P}$ $<.05$ (see Table 2).

Table 2. Regression Analysis of the Relationship between the Scores of SIS Dimensions and OSAQ Total Score

\begin{tabular}{ccccccccc}
\hline Dependent variable & Independent variables & $\mathrm{B}$ & $\mathrm{SE}$ & $(\beta)$ & $\mathrm{t}$ value & Pvalue & $\mathrm{R}^{2}$ & $\mathrm{R}_{\mathrm{adj}}{ }^{2}$ \\
\hline OSAQ total score & PSE & -.183 & .106 & -.101 & -4.518 & $<.001$ & .436 & .433 \\
& PC & -.314 & .149 & -.229 & -2.663 & .032 & & \\
& DFSE & -.191 & .056 & -.128 & -4.113 & $<.001$ & & \\
\hline
\end{tabular}

\section{DISCUSSIONS}

The incidence of Internet addiction was $26.1 \%$ (309/1183), in which the incidence of online shopping addiction was $16.7 \%(198 / 1183)$, and that of female students was $20.5 \%$ $(127 / 620)$, which was significantly higher than that of male students $(12.6 \%, 71 / 563)$, consistent with previous research results [18-20]. It is suggested that both Internet addiction and online shopping addiction are common behavioral problems of college students, and female students are more affected by online shopping addiction.

$762(64.4 \%)$ students were in the intermediate state between identity diffusion and positive delaying while 120 $(10.2 \%)$ in self-identity diffusion, both of which were significantly higher than those in WANG Shuqing's study [24], which may be caused by different research years. It is suggested that the development of college students' self-identity lags behind the physiological age stage.

Multiple stepwise linear regression analysis showed that there was a significant negative correlation between the scores of each dimension of SIS and the total score of OSAQ. It is suggested that the establishment of self-identity can help college students to reduce the tendency of online shopping addiction.

College students with higher degree of self-identity completion have experienced and solved a lot of confusion about themselves, career, ideals and beliefs in the past. They have a relatively full understanding of their own status and future development, a positive desire to invest in life and a high level of investment. Because they have solved many development crises in the past, they have more clear life goals, more stable emotions, better self-control, better resistance to the temptation of the Internet, and lower tendency for online shopping addiction. On the other hand, the college students with lower degree of self-identity are experiencing confusion from youth to adulthood, and they have experienced less crisis in the past. Most of them have not yet defined their life goals, have insufficient understanding of their own status and future development, are prone to generate negative emotions such as confusion, anxiety and depression, and have poor self-control. They are easy to be attracted by the free and independent elements in the online shopping environment and present excessive and increasingly serious online shopping behaviors, so as to reduce and eliminate psychological pressure [25], and get the identity in the world of Internet that has not been obtained in the real world [8].

\section{CONCLUSIONS}

This study preliminarily reveals the relationship between self-identity and online shopping addiction, and verifies the following hypothesis: self-identity negatively predicts college students' online shopping addiction. In other words, the more perfect the self-identity development of college students, the less likely they are to be addicted to online shopping.

To sum up, one of the important reasons for college students' online shopping addiction is the confusion caused by the imperfect development of self-identity. Excessive online shopping can reduce psychological pressure, anxiety and other negative emotions, and obtain the identity that has not been obtained in the real world. In conclusion, the following suggestions for family and school education are put forward: the intervention of college students' online shopping addiction should start with strengthening college students' mental health education and psychological state training, help them improve their self-identity level and self-control ability, define their development direction, obtain identity in the real world, better reduce their negative emotions and enhance self-control. In the future, we can add longitudinal research data to further verify the relationship between college students' self-identity and online shopping addiction.

\section{REFERENCES}

[1] ZHANG Shanshan, CHANG Jian, "Double Eleven" e-commerce transaction volume reached a new record: 1682 billion in Tmall, 1271 billion in JD, City Express. 2017,11,13. DOI: http://tj.people. com.cn/n2/2017/ 1113/c375366 - 30915590. html.

[2] DONG Xiaoying, Among 100 "hands-chopping people", 17 are college students, Beijing Youth Daily. 2017, 09, 07. DOI: 
http://epaper.ynet.com/html/2017-09/07/content 261704. htm? div=-1.

[3] LI Yuxue, Alienation and regression of college students' online shopping, Economic Research Guide.

(4)(2020) 138-141. DOI:

CNKI:SUN:JJYD.0.2020-04-060

[4] ZHANG Yujuan, Research on the relationship between online shopping addiction and academic procrastination, Science and Technology Information. (27)(2018) 249-250. DOI: 10.16661/ j.cnki. 1672 3791.2018.27.249

[5] ZHU Zhengui, GAO Yihan, MAO Yuhuan, Research on the influence of college students' online shopping consumption psychology and behaviors on online entrepreneurship, China Journal of Commerce. (5)(2020) 65-66. DOI:

10.19699/j.cnki.issn2096-0298.2020.09.065

[6] CHEN Jianmei, JIANG Bo, Clinical symptoms, formation mechanism and psychological intervention of online shopping addiction, Frontier. (3)(2010) 177-179. DOI: 10.3969 /j.issn. 1009-8267.2010.03.047

[7] HAN Mei, MIAO Fen, Poll: $71.1 \%$ of respondents think they are "addicted to online shopping", China Youth Daily. 2011, 01, 26 (07). DOI: http://zqb. cyol.com/ html/2011-01/26/nw.D11 0000zgqnb _ 20110126_2-07.htm

[8] JIANG Jianguo, Online shopping addiction: Commodity illusion and circular narcissism, Exploration and Free Views. (3)(2020) 93-96. DOI: CNKI:SUN:TSZM.0.2020-03-016

[9] Haug, Wolfgang Fritz, Kritik Der Warenasthetik: focusing on commodity aesthetics in high-tech capitalist society, Peking University Press, 2013.

[10] Erikson E H, Identity and life cycle, International Universities Press, 1959.

[11] Marcia J E, Development and validation of ego-identity status, Journal of Personality and Social Psychology, 28(3)(1966) 551-558. DOI: https://doi.org/10.1037/h0023281

[12] Azushi Kato, Self-identity and its structure in college students, Educational Psychology Research (Japanese). (31)(1983) 20-30.

[13] ZHANG Risheng, Study on identity and identity states in youth: the composition and self-determination of identity states, Psychological Science. 23(4)(2000) 430-434. DOI:10.16719/j.cnki.1671-6981. 2000. 04.011

[14] Sheldon Stryker, Peter J Burker, The Past, Present, and Future of Identity Theory, Social Psychology Quarterly. 63(4)(2000) 284-298. DOI: $10.2307 / 2695840$

[15] ZHANG Guohua, LEI Li, The relationship between adolescents' peer attachment self-identity and Internet addiction, Chinese Journal of School Health. 29(5)(2008) 454-455. DOI: 10.3969/j.issn.1000-9817. 2008.05 .023

[16] ZHANG Xinyue, DENG Linyuan, Effects of perceived parental conflict and self-identity on adolescents' Internet addiction, Chinese Journal of Clinical Psychology. 23(5)(2015) 906-910. DOI:10.16128/j.cnki.1005-3611.2015.05.034

[17] Cohen Jacob, Statistical power analysis, Curr Direct Psychol Sci. 1(13)(1992) 98-101. DOI: 10.1111/1467-8721.ep10768783

[18] ZHANG Jianying, LIU Huan, ZHANG Ming, WANG Yingying, JIANG Haijiao, ZHANG Zhiyun, Current situation and influencing factors of Internet shopping addiction among college students in Wuhu City, Journal of Shenyang Medical College.

21(1)(2019) 39-42. DOI: 10.16753/j.cnki. 1008-2344. 2019. 01.011

[19] SHI Qingxin, FU Anzhou, Survey of college students' online shopping addiction tendency, Contemporary Youth Research. (2)(2016) 12-17. DOI: 10.3969/j.issn. 1006-1789. 2016.02. 002

[20] ZHU Yu, GAO Xiaoqian, LI Rui, Survey and analysis of college students' online shopping addiction, Journal of Liaoning Technical University (SOCIAL SCIENCE EDITION).17(6)(2015) 633-635. DOI: CNKI:SUN:NLGC.0.2015-06-013

[21] ZHANG Houcan, XU Jianping, Modern psychology and education statistics, Beijing Normal University Publishing Group, 2012.

[22] XU Lang, Preliminary study on online shopping addiction of college students and compilation of questionnaire, Ma.D. Thesis, Central China Normal University, 2014. DOI: CNKI: CDMD:2.1014.238869

[23] LEI Li, YANG Yang, Compilation and validation of adolescents pathological internet use scale, Acta Psychologica Sinica. 39(4)(2007) 688-696. DOI: CNKI:SUN:XLXB.0.2007-04-016 
[24] WANG Shuqing, ZHANG Wenxin, ZHANG Lingling, The relationship between college students' self-identity and identity style, parent-child communication, Psychological Development and Education. 23(1)(2007) 59-65. DOI:

10.3969/j.issn.1001-4918.2007.01.011
[25] ZHANG Congwei, SUN Shaorong, Research on the prevention system of online shopping addiction of middle-aged women under social pressure, E-Business Journal. (10)(2018) 30-34. DOI:

CNKI:SUN:DZKJ.0.2018-10-01 